\title{
D-Dimer Tests in the Emergency Department: Current Insights
}

\author{
Francesca Innocenti (iD \\ Cristian Lazzari \\ Francesca Ricci \\ Elisa Paolucci \\ Ilya Agishev \\ Riccardo Pini
}

Emergency Department High-

Dependency Unit, Department of Clinical

and Experimental Medicine, Careggi

University Hospital, Florence, Italy
Correspondence: Francesca Innocenti Lg. Brambilla 4, Florence, 50I44, Italy Tel +393339117845

Email innocenti.fra66@gmail.com

\begin{abstract}
In the Emergency Medicine setting, D-dimer is currently employed in the diagnostic assessment of suspected venous thromboembolism and aortic syndrome. The nonspecific symptoms reported by patients, like chest pain, dyspnea or syncope, uncover a wide range of differential diagnosis, spanning from mild to life-threatening conditions. Therefore, we assumed the perspective of the Emergency Physician and, in this narrative review, we reported a brief presentation of the epidemiology of these symptoms and the characteristics of patients, in whom we could suspect the aforementioned pathologies. We also reported in which patients D-dimer gives useful information. In fact, when the probability of the disease is high, the D-dimer level is futile. On the contrary, given the low specificity of the test, when the probability of the disease is very low, a false-positive value of the D-dimer only increases the risk of overtesting. Patients with low to moderate probability really benefit from the D-dimer testing, in order to prevent the execution of expensive and potentially dangerous imaging tests. In the second part of the review, we focused on the prognostic value of the test in septic patients. The early prognostic stratification of septic patients remains a challenge for the Emergency Physician, in the absence of a definite biomarker or score to rely on. Therefore, we need several parameters for the early identification of patients at risk of an adverse prognosis and the D-dimer may play a role in this demanding task. SARS COVID-19 patients represent an emerging reality, where the role of the D-dimer for prognostic stratification could be relevant. In fact, in patients with severe forms of this disease, the D-dimer reaches very high values, which appear to parallel the course of respiratory failure. Whether the test may add useful information for the management of these patients remains to be determined.
\end{abstract}

Keywords: venous thromboembolism, aortic syndromes, diagnostic assessment, sepsis, COVID-19, prognostic stratification

\section{Introduction}

D-dimer is the name given to one of the families of fibrin fragments, which form and circulate in the blood-stream for several days after a thrombotic event or in the presence of an abnormal activation of the coagulation process. The test was introduced in clinical practice in the 1970s and it was employed to check for the presence of Disseminated Intravascular Coagulation (DIC). The limited diagnostic ability was due to the low specificity of the test as it detected both fibrin and fibrinogen degradation products. The dramatic improvement of the test, which actually recognizes specifically an epitope on cross-linked fibrin monomers, increased the possible applications as a diagnostic tool. In the clinical setting of Emergency Medicine, D-dimer is a cornerstone test in the diagnostic assessment of 
several conditions, like venous thromboembolism (VTE) or aortic syndromes, for both of which the risk of misdiagnosis and the possibility of overtesting is high. Besides its diagnostic role, a prognostic value in the septic syndrome and, more specifically, in patients with severe forms of infection by SARS COVID-19 is emerging.

We performed a literature review via the PubMed portal after 2016, using ("D-dimer" AND "Emergency Department") as keywords to identify all studies that evaluated the diagnostic and prognostic role of the D-dimer in the Emergency Department (ED). The reference lists from all relevant retrieved manuscripts were further reviewed in order to identify additional studies.

In this narrative review, we will present the role of the D-dimer test in the diagnostic assessment of venous thromboembolism and aortic syndromes, with a special attention on the selection of patients in whom the test may add useful information. In the second part, we will report the available data about the role of the D-dimer in the early prognostic assessment of septic patients and those affected by COVID-19.

\section{What is the D-Dimer?}

Blood clot formation is a complex process involving several molecules and different pathways. A crucial step is the activation of thrombin, which converts soluble fibrinogen to fibrin through the cleavage of fibrinopeptides from the $\mathrm{N}$-terminal domains. Fibrin initially polymers through noncovalent interactions, until factor XIII, activated by thrombin, cross-links the D domains of adjacent fibrin molecules, stabilizing the clot. The degradation of crosslinked fibrin molecules, occurring through plasmin activation during fibrinolysis, leads to fibrinogen degradation products (FDP) and D-dimer generation (Figure 1).

The D-dimer measurement is used as a global marker of activation of the coagulation and fibrinolytic systems, and functions as an indirect marker of thrombotic and subsequent thrombolytic activity ${ }^{1}$ that influences the accuracy of diagnosis of thromboembolism. D-dimer molecules are generated through the degradation of crosslinked fibrin during fibrinolysis. D-dimer generation requires the activity of three enzymes: thrombin, activated factor XIII (factor XIIIa), and plasmin. The process starts when thrombin generated by the coagulation system converts soluble fibrinogen to fibrin monomers. These monomers then form fibrin polymers through noncovalent interactions based on allosteric changes within the protein as a result of thrombin cleavage of fibrinopeptides from the N-terminal domain (Figure 1). Fibrin is strengthened through interactions with factor XIII, which, after activation by thrombin, cross-links the $\mathrm{D}$ domains of adjacent fibrin monomers. Plasmin digestion of the fibrin clot results in the D-dimer molecule

\section{D-Dimer in Blood Assays}

In blood samples, D-dimer is detected through monoclonal antibodies that recognize an epitope on cross-linked D-dimer. This epitope is absent in non-cross-linked fibrin monomers as well as in the D domain of fibrinogen. Although there are numerous commercial D-dimer assays, they are of 3 general types: whole-blood agglutination assays (a semiquantitative assay), enzyme-linked immunosorbent or immunofluorescent assays (ELISA and ELFA) and latex agglutination assays (quantitative assays). ${ }^{2}$

D-dimer results may not be comparable among the various assays because of the employment of monoclonal antibodies with varying specificities for the D-dimer, differences in assay methodology or instrumentation, and variations in the values used to discriminate between normal and pathologic test results. Because of these reasons, standardization of the tests is difficult. ${ }^{2}$

As an additional confounder, two units of D-dimer measurement are currently used in clinical laboratories: Fibrinogen Equivalent Units (FEUs) and D-Dimer Units (DDUs). FEU (340 kD) and DDU (195 kD) may be used interchangeably, considering that FEU is roughly two times the mass of one DDU. Therefore, DDU is obtained by dividing FEU by 2 . Since this is not an exact conversion, it might be appropriate for every laboratory to state its own threshold for abnormality. However, the majority of clinical studies rely on DDU (instead of FEU) for decision making, so this kind of measurement should be preferred. Another difficulty arises from using different measure units (ie, $\mathrm{ng} / \mathrm{mL}, \mathrm{mg} / \mathrm{L}, \mu \mathrm{g} / \mathrm{L}, \mathrm{g} / \mathrm{L}, \mathrm{g} / \mathrm{mL}$, and $\mathrm{mg} / \mathrm{dL}$ ) for reporting $\mathrm{D}$-dimer results.

Among the different measure units, "mg/L" or the corresponding " $\mathrm{ng} / \mathrm{mL}$ " is probably the unit that best approximates the International System of Units (SI). ${ }^{3}$

\section{D-Dimer: A Low Specific Lab Test}

In blood essays, the D-dimer level tends to increase in several clinical conditions, so that its use in the Emergency Department (ED) can be affected by a low diagnostic specificity. Lippi et al collected the D-dimer values of 


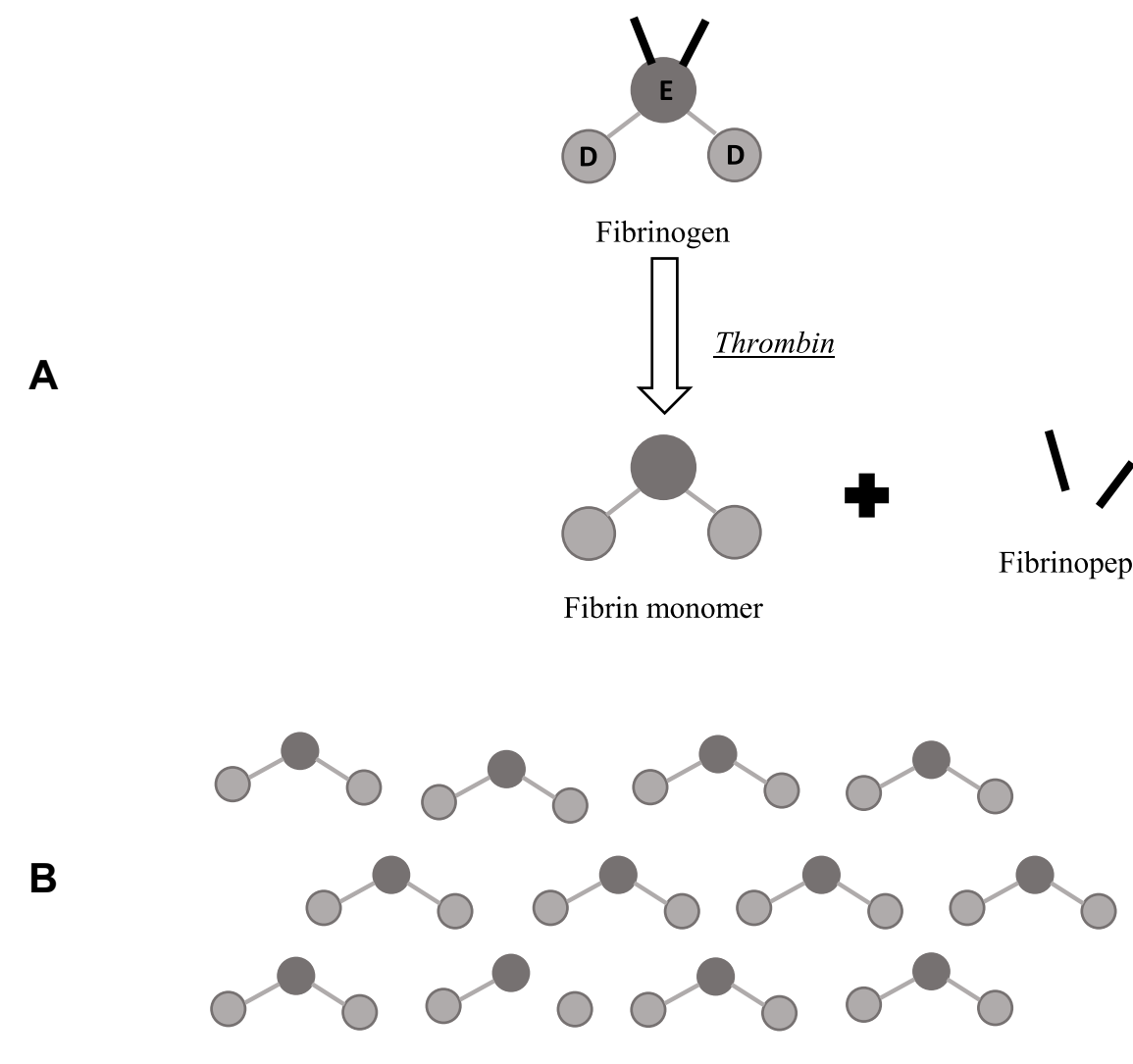

Self-assembling of fibrin monomers

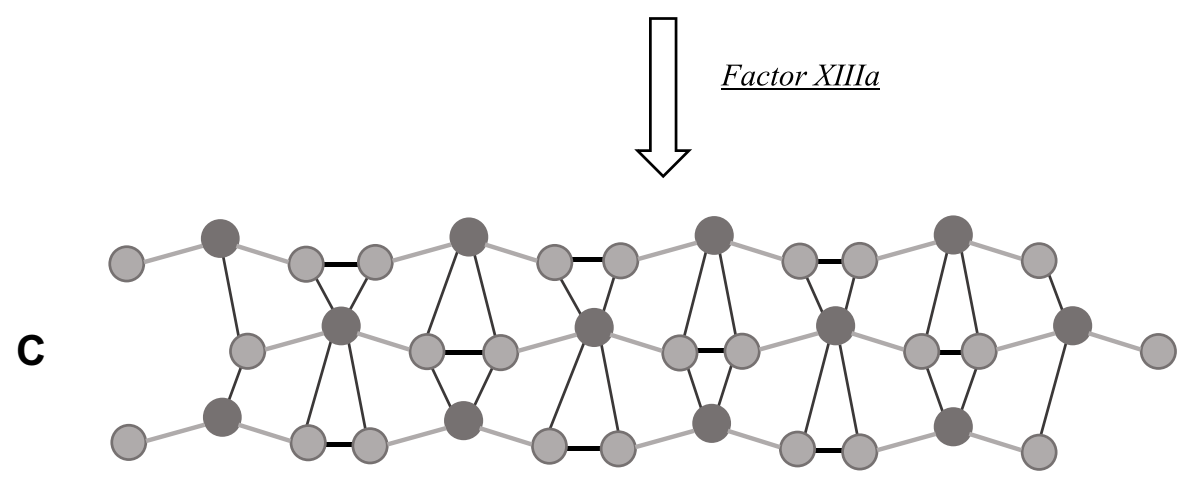

Crossed-linked fibrin polymer

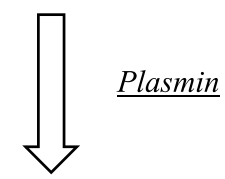

D $\mathrm{D}$-dimer

Figure I The process of D-dimer generation: I) Thrombin cleaves fibrinopeptides from fibrinogen monomer (A); 2) Fibrin monomers aggregate (B); 3) Fibrin monomers are cross-linked by factor XIIla, that stabilizes the fibrin polymer (C); 4) fibrin is degraded by plasmin, releasing D-dimer and fibrinogen degradation products (FDP) (D).

1647 patients accessing the ED with the aim to rule-out or rule-in VTE, regardless of their pre-test clinical probability for VTE. They showed that, in patients with increased D-dimer levels, infection was the most frequent diagnosis
(15.6\%), followed by VTE (12.1\%), syncope $(9.4 \%)$, heart failure $(8.9 \%)$, trauma $(8.2 \%)$ and cancer $(5.8 \%) .{ }^{4}$

In Table 1, we report the most frequent confounding circumstances related to a D-dimer elevation. 
Table I Causes of D-Dimer Elevation

\begin{tabular}{|l|l|}
\hline Pathologic & Non-Pathologic \\
\hline - Thromboembolism: & - Age \\
○ Venous: deep vein thrombosis, pulmonary & - Post-operative state \\
embolism & - Pregnancy and \\
○ Arterial: myocardial infarction, stroke, acute & Cigarette smoking \\
limb ischemia, intracardiac thrombus & \\
○ Disseminated intravascular coagulation & \\
(DIC) & \\
- Infection and sepsis & \\
- Chronic inflammatory diseases & \\
- Trauma & \\
- Malignancy & \\
- Others & \\
○ Renal or liver dysfunction & \\
○ Congestive heart failure & \\
○ Atrial fibrillation & \\
o Preeclampsia & \\
○ Thrombolytic therapy & \\
o Sickle cell disease & \\
\hline
\end{tabular}

Finally, the relationship between the D-dimer and age or between the D-dimer and renal function will be discussed elsewhere, because of the possibility to adequate the cut-off in the presence of these conditions.

\section{Role of D-Dimer in the Evaluation of Patients with Suspect Pulmonary Embolism}

D-dimer has a pivotal role in the diagnostic pathway of PE. Dyspnea and loss of consciousness represent two of the more common symptoms among patients, in whom we have to ascertain the presence of PE. Therefore, as these symptoms are common among patients who come to the $\mathrm{ED}$, the challenge is to identify among them those who require a complete workout and to apply the correct decision rules, in order to prevent misdiagnosis.

\section{Dyspnea as Chief Complaint:} Epidemiology and Clinical Characteristics Dyspnea is defined by the American Thoracic Society as the "subjective experience of breathing discomfort that consists of qualitatively distinct sensations that vary in intensity"; 5 a wide variety of distinctive mechanisms can result in the common sensation of dyspnea. Misdiagnosis has been shown to increase morbidity, cost and time to discharge. $^{6}$

The reported prevalence of PE in patients presenting with dyspnea is very heterogeneous, ranging from $4 \%{ }^{7}$ to
$38 \%{ }^{8}$ Among patients diagnosed with PE, ${ }^{9}$ dyspnea was the most common presenting symptom, reported by up to $73 \%$ of subjects, ${ }^{10}$ which was more frequent during rest than during exertion ( $61 \%$ vs $16 \%)$, with rapid onset reported by $67 \%$ of all patients. ${ }^{11-13}$ The clinical signs and symptoms of acute PE are non-specific. In most cases, PE is suspected in a patient with dyspnea, eventually associated with chest pain, presyncope or syncope, or hemoptysis. ${ }^{14}$

\section{Syncope as Chief Complaint: Epidemiology and Clinical Characteristics} Syncope is defined as a transient loss of consciousness (TLOC) due to cerebral hypoperfusion, characterized by a rapid onset, short duration, and spontaneous and complete recovery. ${ }^{15}$ Syncope is a common presenting symptom in the ED, accounting for $1 \%$ to $3 \%$ percent of all ED visits. ${ }^{16}$

Focusing on non-traumatic TLOC, the latest ESC Guidelines for the diagnosis and management of syncope $^{15}$ individuate three main groups, ie, reflex, cardiovascular, and secondary to orthostatic hypotension.

Beyond classifications, in a patient with a chief complaint of syncope, the major aim in the ED is to exclude life-threatening causes, such as cardiac syncope, blood loss, pulmonary embolism and subarachnoid haemorrhage. The D-dimer is useful when we suspect pulmonary embolism, deep venous thrombosis (DVT) and aortic syndrome. Aortic dissection will be discussed elsewhere in a dedicated paragraph. The suspicion and diagnosis of PE is important because a highly effective treatment such as oral anticoagulation is available and can significantly improve patients' prognosis.

In patients with suspected EP and hemodynamic instability, the diagnostic work-up does not include the D-dimer measurement. According to ESC Guidelines, ${ }^{14}$ those patients should undergo computed tomography pulmonary angiography (CTPA) only if it is immediately available and feasible; otherwise, they should receive early anticoagulation treatment. Anyway, when syncope is the presenting symptom, even in the absence of hemodynamic instability, PE is associated with a higher prevalence of right ventricle (RV) dysfunction and early mortality. ${ }^{17}$ The main causes of syncope during PE are RV dysfunction, with reduced cardiac output and peripheral hypoperfusion, arrhythmias and hypoxemia. ${ }^{18}$ 
However, the prevalence of PE in patients with syncope is largely debated. According to the results of the PESIT study, ${ }^{19}$ acute PE was identified in nearly one out of six patients hospitalized for a first episode of syncope. In this study, patients' median age was higher ( 80 years) than in the following ones: all recruited patients were hospitalized and they underwent a systematic workup for PE: the clinical probability assessment was performed by the Wells score, D-dimer was evaluated and CT or lung scan imaging was performed if either was abnormal. ${ }^{19}$ The very high prevalence obtained is in contrast with the results of many other studies. In a prospective diagnostic study $(B A S E L ~ I X)^{20}$ among 1397 patients from 8 different countries, PE was diagnosed in $1.4 \%$ of patients with the complaint of syncope in the ED, in $2.3 \%$ of those hospitalized for syncope and in $4.3 \%$ of those hospitalized for the first episode of syncope. Patients underwent screening for PE, by Wells score and D-dimer, when additional symptoms were present (ie, dyspnea), based on clinical judgment. Other large observational studies reported low prevalence of PE among patients with the same complaint. ${ }^{21-23}$

\section{Role of Clinical Prediction Rules and D-Dimer in the Diagnostic Assessment}

In patients with suspected $\mathrm{PE}$, both presenting with dyspnoea or syncope, associated symptoms such as chest pain or haemoptysis should be investigated. ${ }^{14}$ Arterial blood gas can show hypoxaemia and hypocapnia, but about $40 \%$ of patients with PE show normal arterial oxygen saturation and $20 \%$ normal alveolar-arterial oxygen gradient. ${ }^{24,25}$ In addition to symptoms, knowledge of the predisposing factors for VTE is important in determining the clinical probability of the disease, which increases with the number of predisposing factors. However, in $40 \%$ of patients with $\mathrm{PE}$, no predisposing factors were found. ${ }^{26}$

The combination of symptoms and clinical findings with the presence of predisposing factors for VTE allows the classification of patients with suspected PE into distinct categories of clinical or pre-test probability, which corresponds to an increasing actual prevalence of confirmed PE. As the post-test (ie, after an imaging test) probability of PE depends not only on the characteristics of the diagnostic test itself but also on the pretest probability, this is a key step in all diagnostic algorithms for PE. In fact, given the low specificity of all the clinical signs and the great availability of angio-CT scan, an increased performance of this test has been observed in the clinical practice, without a certain benefit on the prognosis and mortality rate of patients with suspected PE. In real clinical practice, overtesting is very frequent. A prospective observational study including 3024 patients visiting the ED for shortness of breath and/or chest pain showed that, despite guidelines, many patients still underwent testing for PE trough CT or V/Q scan even if Pulmonary Embolism Rule Out Criteria (PERC)-negative and without the D-dimer risk stratification $(25.5 \%$ of PERC-negative). It is still interesting to notice that in the PERC-negative sample, $0.4 \%$ of patients received a diagnosis of PE vs $2.2 \%$ of PERC-positive patients. ${ }^{27}$

Several strategies have been proposed to reduce PE overtesting $^{28}$ and avoid CTPA, which exposes patients to the risk of allergies, kidney failure and cumulative radiation-induced cancer. Of these, the most frequently used prediction rules are the revised Geneva rule and the Wells rule (Table 2) that divide patients into different groups according to their likelihood of having DVT/PE. Alongside the scores, the diagnosis of VTE is strongly supported by laboratory testing and the D-dimer measurement is currently considered the biochemical gold standard in the diagnostic assessment of patients with suspected VTE. ${ }^{29}$ Multiple trials have confirmed the safety of using a clinical decision rule to determine a pre-test probability of PE in combination with D-dimer assay to rule out PE. ${ }^{13}$

In a typical VTE diagnostic algorithm, patients who are scored as "low" or "unlikely" to have VTE have a drawn D-dimer level. If the D-dimer result is negative, VTE is considered excluded and no further testing is performed. For patient with low $(<15 \%)$ pre-test probability, this is the primary role of a D-dimer assay: to safely exclude the diagnosis of VTE without requiring further investigation. ${ }^{14}$

On the other hand, if the D-dimer result is positive, imaging tests are ordered. If the patient is given a "moderate/high" or "likely" score to have VTE, D-dimer testing is omitted and imaging tests are performed (Figure 2).

Regardless of the score used, the proportion of patients with confirmed PE can be expected to be $<10 \%$ in the lowprobability category, $30 \%$ in the moderate-probability category, and $65 \%$ in the high probability category. When the two-level classification is used, the proportion of patients with confirmed PE is $<12 \%$ in the PE-unlikely category and $30 \%$ in the PE-likely category. ${ }^{30}$

A D-dimer result is not helpful when the pretest probability of VTE is "likely" for three reasons: (i) the result is 
Table 2 Clinical Risk Score to Define the Pretest Probability of Pulmonary Embolism (PE) in Patients with Suspect Symptoms

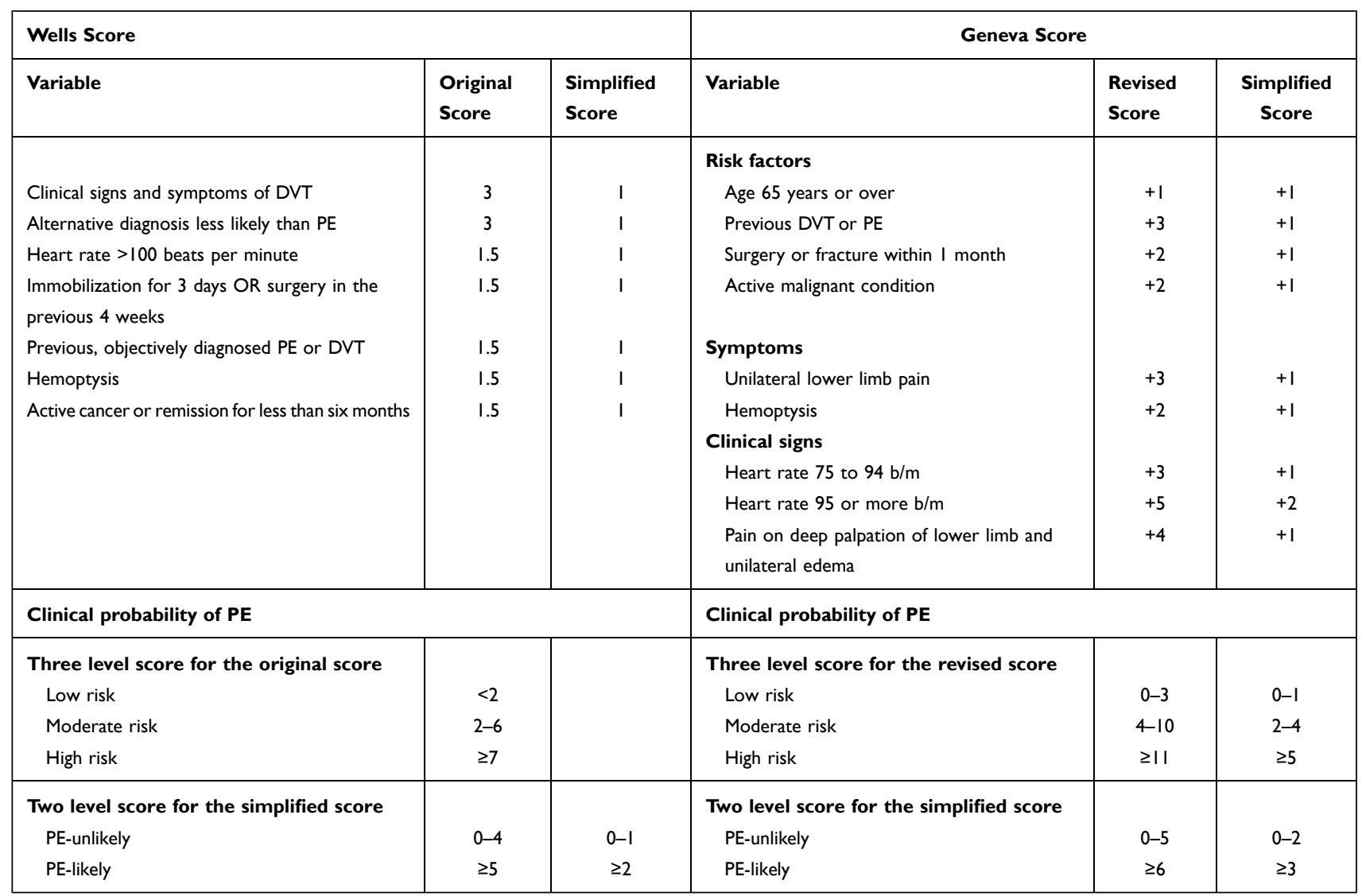

unlikely to be negative even if VTE is not present (ie, many of the factors that increase the risk of VTE will also increase D-dimer levels, eg, cancer, recent surgery); (ii) a positive result still requires confirmatory imaging; and (iii) there is uncertainty that the D-dimer testing can safely exclude VTE in this subgroup. ${ }^{31}$

We cannot ignore that even though $\mathrm{D}$-dimer is a relatively low-cost test, it has poor specificity, and therefore often leads to false-positive results, especially among low-risk patients. However, once the D-dimer test is positive, the physician has to perform a confirmatory test. To deal with such an issue, in recent years, several rule-out scores have been developed, with the aim to identify patients who do not require any further diagnostic assessment (Table 3), specifically no D-dimer dosage or CTPA, or V/Q scan. The drawback of the PERC rule is the need to employ a double score, as it can be applied only in patients already classified as low risk by revised Geneva score.

Other strategies have therefore been proposed to reduce PE overtesting and overdiagnosis. ${ }^{28}$ Two main novelties characterize the new tools: the use of one only prediction score and the adoption of different cut-offs for the D-dimer based on the probability of PE. Roy and coll. developed and validated a pretest probability score (Table 3) to safely reduce imaging testing by integrating all the previously proposed strategies: the 4-Level Pulmonary Embolism Clinical Probability Score (4PEPS). With this score they classified patients in four subgroups: 1) very low clinical pretest probability - CPP (score $=0$ ), allowing exclusion of $\mathrm{PE}$ on clinical criteria only; 2) low CPP, allowing exclusion of PE with a D-dimer level less than $1000 \mathrm{ng} / \mathrm{mL}$; 3) moderate CPP, allowing exclusion of PE with a D-dimer level less than $500 \mathrm{ng} / \mathrm{mL}$ or less than the age-adjusted cutoff value; 4) high CPP, not allowing a safe exclusion of PE with D-dimer testing and requiring imaging testing (CTPA or V/Q scan). The accuracy, safety, and efficacy of the 4PEPS strategy were confirmed in 2 independent external validation cohorts, one with a moderate PE prevalence and the other with a high PE prevalence. For both cohorts, 4PEPS score allowed to obtain a very low rate of diagnostic failure and a substantial reduction in imaging testing. It should now be tested in a formal outcome study. With 


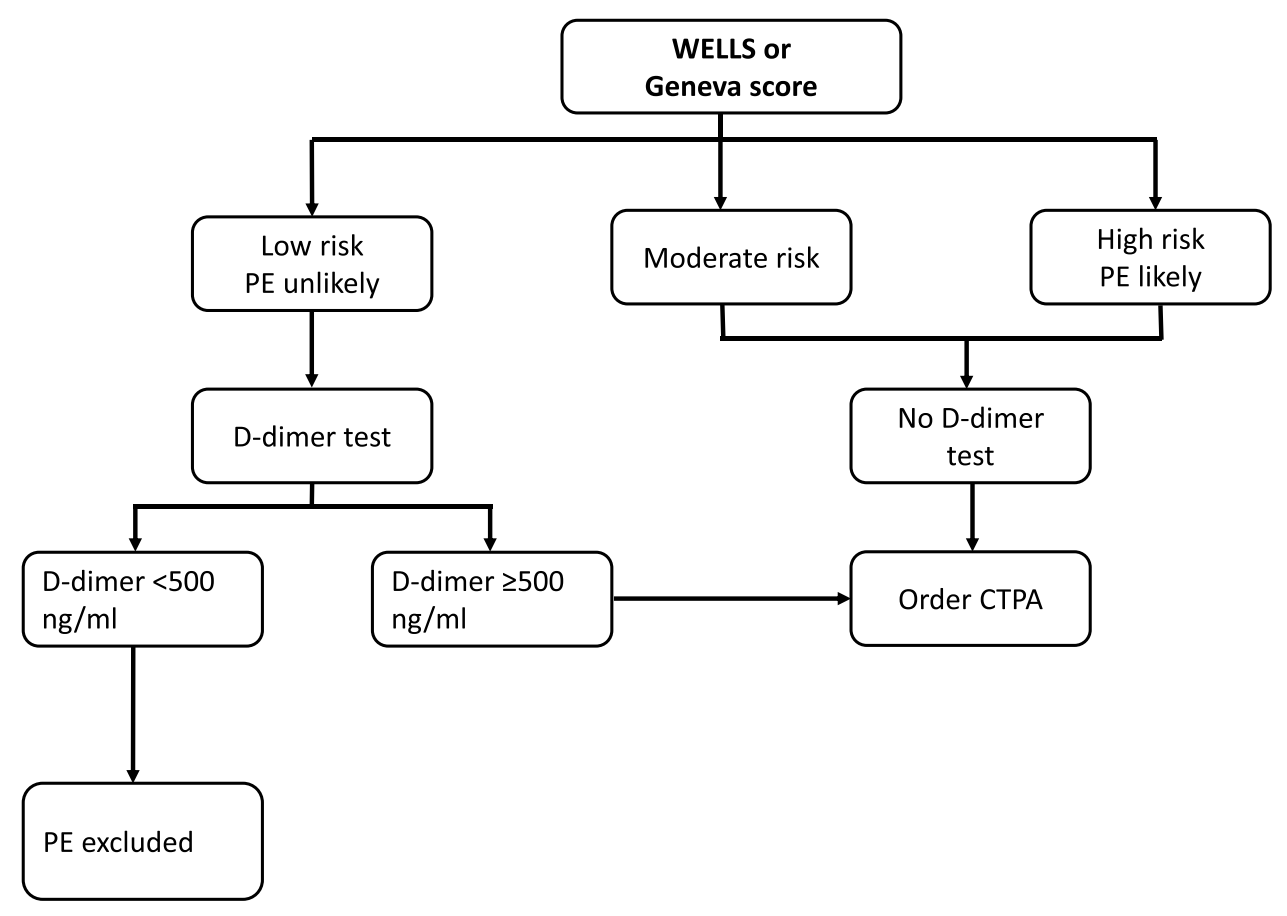

Figure 2 Diagnostic pathways in patients with suspected PE based on WELLS and GENEVA scores.

the YEARS $^{32}$ strategy (Table 3), pulmonary embolism is considered to be ruled out in patients with zero YEARS criteria and a D-dimer level of less than $1000 \mathrm{ng} / \mathrm{mL}$ and in those with one or more YEARS criteria and a D-dimer level of less than $500 \mathrm{ng} / \mathrm{mL}$. Finally, the Pulmonary Embolism Graduated D-Dimer (PEGeD) ${ }^{33}$ strategy used the 3-level revised Wells score and PE could be ruled out in patients with a moderate pre-test probability, who have a D-dimer level of less than $500 \mathrm{ng} / \mathrm{mL}$ or in patients with a low CPP who have a D-dimer level of less than $1000 \mathrm{ng} /$ $\mathrm{mL}^{33}$

It is of utmost importance to first examine the patient and assess the clinical probability, after which the D-dimer concentration can be considered, in order to prevent physicians from being influenced by a normal D-dimer test result when they evaluate the clinical probability of PE. Patients with a likely clinical probability should undergo further testing, regardless of the D-dimer test outcome. Gibson et $\mathrm{al}^{34}$ found that in patients with an unlikely probability of PE $(n=477)$, VTE was confirmed in $1.1 \%$ of the patients with a normal D-dimer concentration. In those patients with a likely clinical probability of PE $(\mathrm{n}=$ 86), VTE was confirmed in $9.3 \%$ of the patients with a normal D-dimer concentration.

Actual guidelines recommend the application of Wells or Revised Geneva score, combined with D-dimer evaluation and imaging test when necessary. Only PERC criteria are recommended as a rule-out strategy. The adoption of new scores and the consideration of differential cutoffs based on the level of pre-test probability of PE could offer new opportunities for the appropriate selection of patients to evaluate by the mean of imaging tests. Physicians need reliable and validated instruments as the decision to exclude PE from differential diagnosis may have heavy prognostic consequences in the case of a mistake.

\section{Role of D-Dimer in the Evaluation of Chest Pain}

Chest pain is the second most common specific principal reason given by adult patients (aged $>15$ years old) for visiting the ED, accounting for approximately $6 \%$ of the ED visits yearly. ${ }^{35}$ Among all the possible causes of chest pain, PE, acute coronary syndrome (ACS), and acute aortic syndrome (AAS) are the most life-threatening pathologies that need fast diagnosis and treatment to mitigate the risk of short- and long-term fatal and non-fatal complications. When PE presents itself as chest pain, a differential diagnosis with ACS has to be done, considering that both troponin and D-dimer can be increased in both conditions. A recently published retrospective observational study by 
Table 3 Probability Scores to Rule Out PE

\begin{tabular}{|c|c|c|c|c|c|}
\hline \multicolumn{2}{|l|}{ PERC Criteria } & \multicolumn{2}{|l|}{ 4PEPS } & \multicolumn{2}{|l|}{ YEARS } \\
\hline Variable & Score & Variable & Score & Variable & Score \\
\hline $\begin{array}{l}\text { Age }>50 \text { yrs } \\
\text { Heart rate } \geq 100 \mathrm{~b} / \mathrm{min} \\
\mathrm{O}_{2} \text { sat. on Room air }<95 \% \\
\text { Prior history of DVT/PE } \\
\text { Recent surgery } \\
\text { Hemoptysis } \\
\text { Exogenous estrogen }\end{array}$ & $\begin{array}{l}\text { No } \\
\text { No } \\
\text { No } \\
\text { No } \\
\text { No } \\
\text { No } \\
\text { No }\end{array}$ & $\begin{array}{l}\text { Age, years } \\
<50 \\
50-64 \\
\text { Chronic respiratory disease } \\
\text { Heart rate }<80 \text { beats per minute } \\
\text { Chest pain and acute dyspnea } \\
\text { Male } \\
\text { Hormonal estrogenic treatment } \\
\text { Personal history of VTE } \\
\text { Syncope } \\
\text { Immobility within the last } 4 \text { weeks } \\
\text { Pulse oxygen saturation }<95 \% \\
\text { Calf pain and/or unilateral lower limb } \\
\text { edema } \\
\text { PE is the most likely diagnosis }\end{array}$ & $\begin{array}{l}-2 \\
-1 \\
-1 \\
-1 \\
+1 \\
+2 \\
+2 \\
+2 \\
+2 \\
+2 \\
+3 \\
+3 \\
+5\end{array}$ & $\begin{array}{l}\text { Signs of deep vein thrombosis } \\
\text { Hemoptysis } \\
\text { PE as the most likely diagnosis }\end{array}$ & $\begin{array}{l}1 \\
1 \\
1\end{array}$ \\
\hline $\begin{array}{l}\text { - To be applied only in patients at } \\
\text { low risk based on Geneva score. } \\
\text { - If all criteria are equal to "No", } \\
\text { PE can be ruled out. } \\
\text { - Imaging is mandatory in the } \\
\text { presence of one or more criteria } \\
\text { equal to "Yes" }\end{array}$ & & $\begin{array}{l}\text { Clinical pretest probability } \\
\text { Very low (<2\%): PE can be ruled out } \\
\text { Low }(2-20 \%) \text { : PE can be ruled out if } \\
\text { D-dimer level }<1.0 \mu \mathrm{g} / \mathrm{mL} \\
\text { Moderate }(20-65 \%) \text { : PE can be ruled } \\
\text { out if D-dimer level }<0.5 \mu \mathrm{g} / \mathrm{mL} \text { or }<\text { (age } \\
\times 0.0 \mathrm{I}) \mu \mathrm{g} / \mathrm{mL} \\
\text { High }(>65 \%) \text { : PE cannot be ruled out } \\
\text { without imaging testing }\end{array}$ & $\begin{array}{l}<0 \\
0-5 \\
6-12 \\
\geq 13\end{array}$ & $\begin{array}{l}\text { Diagnostic algorithm } \\
\text { YEARS }=0 \text { and D-dimer } \\
<1000 \mathrm{ng} / \mathrm{mL} \\
\text { YEARS }=0 \text { and D-dimer } \\
\geq 1000 \mathrm{ng} / \mathrm{mL} \\
\text { YEARS } \geq 1 \text { and D-dimer }<500 \\
\mathrm{ng} / \mathrm{mL} \\
\text { YEARS } \geq I \text { and D-dimer } \\
\geq 500 \mathrm{ng} / \mathrm{mL}\end{array}$ & $\begin{array}{l}\text { PE excluded } \\
\text { Order CTPA } \\
\text { PE excluded } \\
\text { Order CTPA }\end{array}$ \\
\hline
\end{tabular}

Kim et $\mathrm{al}^{36}$ proposes a new tool that could be useful in the differential diagnosis between PE with troponin elevation and NSTEMI. The authors elaborated and analyzed the clinical performance of the D-dimer/Troponin ratio in 771 patients with NSTEMI and 90 patients with PE and troponin elevation. According to these authors, PE should be considered in patients with acute chest pain or dyspnea and D-dimer/troponin ratio $>1.82$ before considering acute NSTEMI and performing coronary angiography. The authors concluded that the implementation in the routine clinical practice of D-dimer/troponin ratio could avoid unnecessary coronary angiography. However, prospective studies are needed to confirm these results.

Regarding the presentation of the disease, a case-control study by Ohle et $\mathrm{al}^{37}$ reported that the chest represented the most common pain site with a sensitivity of $69.6 \%$ and a specificity of $52.8 \%$ (LR+ of 1.48) in patients with AAD. Moreover, this study showed that the characteristics (abrupt-onset, tearing/ripping, pleuritic, migrating) and the location (back) of pain, rather than the pain itself, led to an increased likelihood of AAD. Abrupt-onset pain had the highest sensitivity (96.9\%) and tearing/ripping quality had the highest specificity (99.7\%) for detecting AAD.

AASs are relatively rare. ${ }^{38,39}$ In the general population, they affect 5-15 cases/100,000 individuals/year. They include aortic dissection (AD), intramural hematoma (IMH) and penetrating aortic ulcer (PAU) with different percentages based on the type of AAS. In-hospital mortality rate approaches $26 \%$ in patients with type $\mathrm{A} \mathrm{AD}$ or $\mathrm{IMH}^{40-43}$ The diagnostic accuracy of signs and symptoms is limited. ${ }^{44,45}$ Atypical presentations of AAS occur more frequently in women, diabetics and the elderly. ${ }^{46}$

In 2011, Rogers and coll. developed the aortic dissection detection risk score (ADD-RS, Table 4), which allowed for the subdivision of patients visiting the ED with suspected AAS into three different risk classes. In the original score, the D-dimer was not considered and the level of risk was determined based on anamnestic data and 
Table 4 Aortic Dissection Detection Risk Score (ADD-RS)

\begin{tabular}{|l|l|l|}
\hline $\begin{array}{l}\text { Predisposing } \\
\text { Conditions }\end{array}$ & $\begin{array}{l}\text { Pain } \\
\text { Characteristics }\end{array}$ & Physical Findings \\
\hline $\begin{array}{l}\text { Connective tissue } \\
\text { diseases (eg Marfan) }\end{array}$ & Sudden & $\begin{array}{l}\text { Pulse deficit or } \\
\text { anysosfigmia }(>20 \mathrm{~mm} / \\
\mathrm{Hg})\end{array}$ \\
\hline $\begin{array}{l}\text { Familiar history of } \\
\text { aortic disease }\end{array}$ & Severe & $\begin{array}{l}\text { Neurological deficit } \\
\text { plus pain }\end{array}$ \\
\hline Aortic valve disease & $\begin{array}{l}\text { Tearing or } \\
\text { ripping }\end{array}$ & $\begin{array}{l}\text { New diastolic aortic } \\
\text { murmur }\end{array}$ \\
\hline $\begin{array}{l}\text { Thoracic aorta } \\
\text { aneurism }\end{array}$ & Hypotension or shock \\
\hline $\begin{array}{l}\text { Previous aortic } \\
\text { manipulation }\end{array}$ & & \\
\hline
\end{tabular}

Note: I point for each category if one or more risk factors are present (total may vary from 0 to 3 ).

clinical signs. The ADvISED prospective multicenter study proposed to integrate the score with the dosage of the D-dimer in patients with low to moderate pretest probability of having AAS. ${ }^{47}$ In fact, as well as for PE, patients with organ ischemia or hemodynamic instability require urgent diagnosis and treatment and D-dimer evaluation is not useful in these conditions. ${ }^{48}$ In high-risk patients, the D-dimer dosage was negative $(<500 \mathrm{ng} / \mathrm{mL})$ in a significant number of cases, leading to a failure rate of $4.4 \%$. On the other hand, in patients with low-intermediate risk (ADD- $R S \leq 1$ ), who represented the vast majority of screened subjects, the integration of the ADD- $R S$ score with the D-dimer test allowed to exclude AASs with a good accuracy and a failure rate of $0.3 \%$. In fact, in the presence of ADD- $R S=0$ plus D-dimer $<500 \mathrm{ng} / \mathrm{mL}$ or ADD- $R S \leq 1$ plus D-dimer $<500 \mathrm{ng} / \mathrm{mL}$, AAS could be ruled out, with a considerable sparing of expensive and potentially dangerous tests. In the presence of ADD- $R S \leq 1$ and increased D-dimer level, a CTA was indicated (Figure 3). Once again, D-dimer allowed to improve the diagnostic pathway in patients in the intermediate-low risk class.

\section{D-Dimer and Age}

The frequency of abnormally elevated D-dimer levels is higher in older individuals, even in the absence of detectable thrombosis. In particular, the diagnostic specificity of the D-dimer in pulmonary embolism (PE) decreases steadily with age to $10 \%$ in patients in their eighties. ${ }^{49}$ The reason for the increased levels of the D-dimer in the elderly is not completely clear. As proposed by Tita-Nwa et al, a valid hypothesis is the mild pro-inflammatory state, which is "normally" seen in elderly patients. In agreement with this explanation, a reliable marker of systemic inflammation like erythrocyte sedimentation rate was shown to be independently associated with elevated D-dimer levels. $^{50}$

The use of age-adjusted cut-offs may improve the diagnostic performance of D-dimer testing in the elderly. A multinational prospective management study, including 3346 patients, evaluated a previously validated ageadjusted cut-off (for patients aged $>50$ years, normal values $<$ age* $10 \mathrm{ng} / \mathrm{mL}$, ie, for a 70 -year-old man maximal normal value $700 \mathrm{ng} / \mathrm{mL}$ ). The 3 -month failure rate in patients with a D-dimer level higher than $500 \mathrm{ng} / \mathrm{mL}$ but below the age-adjusted cutoff was $0.3 \%$, comparable with that of patients with D-dimer $<500 \mathrm{ng} / \mathrm{mL}$ and negative Computerized Tomographic Angiography (CTA). The use of the age-adjusted (instead of the "standard" $500 \mathrm{ng} / \mathrm{mL}$ ) D-dimer cut-off increased five-fold the number of patients in whom PE could be ruled out without further testing from $6.4 \%$ to $30 \%{ }^{51}$ The ESC 2019 guidelines for the diagnosis and management of $\mathrm{PE}$ recommend the use of the age-adjusted (instead of the "standard" $500 \mathrm{ng} / \mathrm{mL}$ ) D-dimer cut-off. ${ }^{14}$

\section{D-Dimer and Renal Function}

In patients with renal insufficiency, D-dimer levels are elevated, as elimination partly occurs via the kidneys and, on the other hand, renal dysfunction is typically associated with a state of chronic hypercoagulation. This poses a considerable problem to physicians as the possibility of thromboembolic events in these patients is high but the specificity of D-dimer is reduced. In order to overcome this limit, Pfortmueller et al conducted a study on 9716 critically ill patients with suspected VTE. The population was divided into three groups based on the estimated Glomerular Filtration Rate (eGFR). In the presence of kidney failure, D-dimer cutoff values rose with declining eGFR. Three different D-dimer levels (333 ng/mL, 1306 $\mathrm{ng} / \mathrm{mL}$ and $1663 \mathrm{ng} / \mathrm{L}$ ) were identified as cutoff for each of the following classes of renal impairment: 1) eGFR $>60 \mathrm{~mL} / \mathrm{min}$; 2) eGRF $30-60 \mathrm{~mL} / \mathrm{min}$; 3) eGRF $<30 \mathrm{~mL} / \mathrm{min}$, respectively. The new cut-offs could be used to safely rule out VTE with the same sensitivity and specificity as the usual cut-off $(500 \mathrm{ng} / \mathrm{mL})$ in patients with abnormal kidney function, with a post-test probability of VTE of $1 \%{ }^{52}$ 


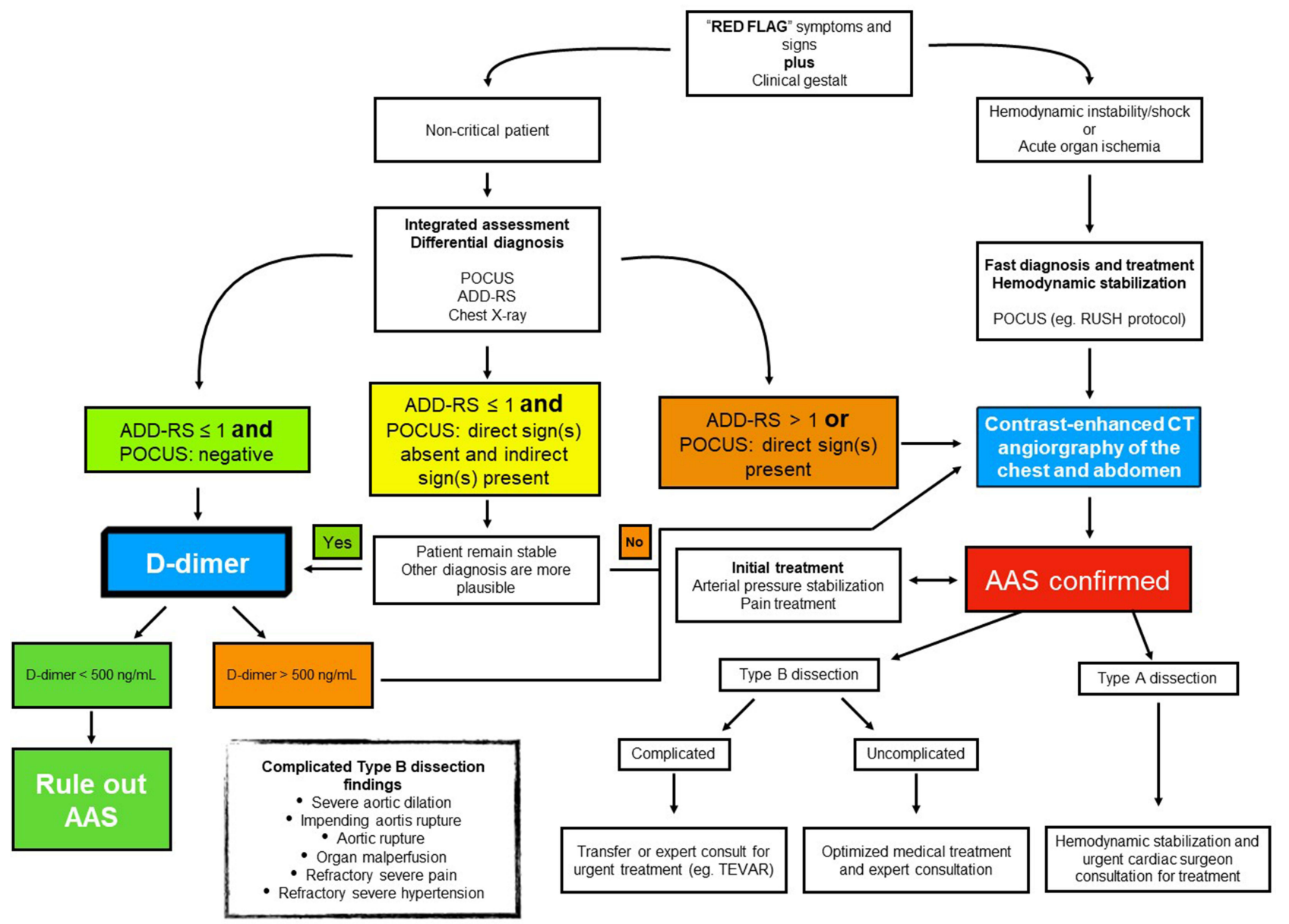

Figure 3 Diagnostic pathway in patients with suspected AAS.

Abbreviations: POCUS, point-of-care ultrasonography; AAS, Acute aortic syndromes; ADD-RS, Aortic dissection risk score.

Schefold et al underlined the use of eGFR adjusted D-dimer cutoff levels. They included 14,477 patients admitted to the ED for suspected VTE and showed that adjusted D-dimer cutoff levels seemed reliable also in patients with acute kidney injury (AKI) and "acute on chronic" renal dysfunction: when eGFR-adjusted D-dimer cutoff levels were used in patients with AKI, the Negative Predictive Value (NPV) remained high (99\%) with a sensitivity of $96 \%$ and a specificity of $39 \%$. In patients with "acute on chronic" renal dysfunction, the use of renal function-adjusted D-dimer values showed a sensitivity of $98 \%$, a specificity of $49 \%$ with an NPV of $98 \% .{ }^{53}$ However, we have to emphasize that the use of clinical decision rules based on age-adjusted D-dimer values is well established, especially for the diagnosis of PE. On the other side, the diagnostic performance of a D-dimer value adjusted for renal function is not definitively validated and requires further investigations.

\section{Prognostic Value of D-Dimer in the ED}

\section{D-Dimer and Sepsis}

According to the Surviving Sepsis Campaign (2016), sepsis has been defined as a life-threatening organ dysfunction caused by a dysregulated host response to infection. ${ }^{54,55}$

Currently, the mortality for sepsis is still high, ranging between $20 \%$ and $50 \%$ in patients with septic shock. ${ }^{56}$ The main determinant of the adverse prognosis of septic patients is the abnormal response of the host to the infection, rather than the infection itself. The abnormal activation of several pathways involved in the immune response finally leads to multi-organ failure (MOF), related to cellular dysfunction and tissue hypoperfusion. The activation of cell death pathways and the presence of mitochondrial dysfunction compromise several essential cellular processes. On the other side, a complex imbalance of circulatory function exists, with reduced peripheral resistances 
and impaired cardiac function, alongside endothelial dysfunction and the abnormal activation of the coagulation system. $^{57}$

Coagulative alterations are virtually recognized in all patients with sepsis: they range from a subtle asymptomatic activation of coagulation to a serious systemic involvement of small vessels (50-70\% of patients), leading to the clinical picture of a DIC (35\% of patients). This spectrum of clinical manifestations is sustained by a derangement of coagulation and fibrinolysis mediated by several cytokines, such tumor necrosis factor (TNF), interleukin-6 (IL-6) and interleukin-1 (IL-1). ${ }^{58}$ These cytokines are responsible for the expression of tissue factor (TF) on monocytes and macrophages, as well as on the damaged endothelial cells, and it has been recognized as the main initiator of coagulation in sepsis, together with other clotting factors, such as factor VIIa, factor Xa, thrombin and fibrin. ${ }^{59}$ On the other hand, especially in cases of overt DIC occurring in septic patients, the prothrombotic effects have shown to be significantly enhanced by the excessive suppression of fibrinolysis caused by overproduction of plasminogen activator inhibitor-1 (PAI-1, Figure 4). ${ }^{60}$

According to the International Society of Thrombosis and Hemostasis (ISTH), D-dimer evaluation has shown its utility in stratifying septic patients in the light of the severity of the coagulopathy, as part of the DIC score, altogether with the values of fibrinogen, international normalized ratio (INR) and platelet count. ${ }^{61}$

Early identification of patients at high risk of an adverse prognosis is still a challenge for the Emergency Physician. SOFA (Sequential Organ Failure Assessment) score has been adopted as a diagnostic tool in the screening of potentially septic patients, but several studies confirmed its good ability to predict in-hospital mortality. ${ }^{62}$

In the actuality, we do not have a specific and reliable biomarker for the diagnostic assessment of septic patients. On the other side, a constellation of tests, including

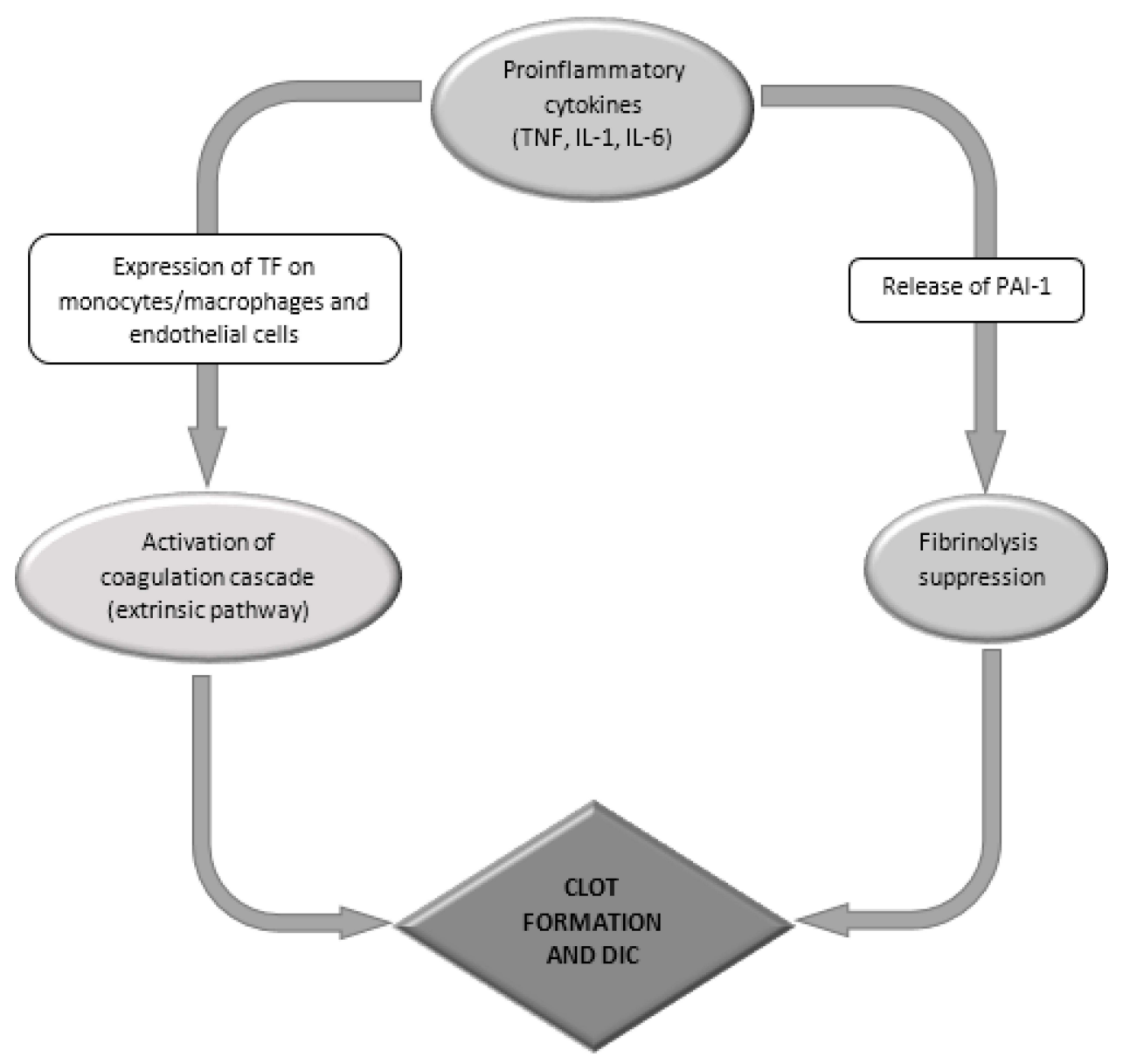

Figure 4 Coagulation abnormalities during sepsis.

Abbreviations: TNF, Tumor Necrosis Factor; II, Interleukin; TF, Tissue Factor; PAI, plasminogen activator inhibitor; DIC, Disseminated Intravascular coagulation. 
D-dimer, are usually employed to assess the severity of the septic process, in order to improve prognostic stratification. D-dimer has shown to add prognostic information to the SOFA score. In a study performed by our group, coagulation parameters commonly measured in clinical practice and used in SOFA score calculation (prothrombin time [PT], activated partial thromboplastin time [aPTT], fibrinogen and platelets) were shown not to provide any useful prognostic information in septic patients. Conversely, higher levels of D-dimer and thrombinantithrombin complex (TAT) levels, measured in sequential evaluations performed in the first 24 hours after ED admission, were significantly associated with an increased short- and medium-term in-hospital mortality, independently to SOFA score and lactate levels. ${ }^{63}$

Likewise, Rodelo et al studied the relationship between a 28-day mortality and several biomarkers (such D-dimer, $\mathrm{C}$ reactive protein, procalcitonin) and scores (SOFA score and APACHE II [Acute Physiologic Assessment and Chronic Health Evaluation II] score). D-dimer was found to be the only biomarker that exhibited a strong linear relationship with 28 -day mortality. ${ }^{64}$

\section{D-Dimer and COVID-19}

The coronavirus disease 2019 (COVID-19) pandemic, due to the novel Severe Acute Respiratory Syndrome Coronavirus 2 (SARS-CoV-2), has caused worldwide over 176 million confirmed cases of COVID-19, including 3.8 million deaths.

SARS-CoV-2 infection may be asymptomatic or it may cause a wide spectrum of symptoms, ranging from mild symptoms of upper respiratory tract infection and pneumonia to multiorgan failure, configuring an overt lifethreatening disease. ${ }^{65}$

Besides the respiratory failure, that represents the hallmark of COVID-19-related pneumonia, the coagulation abnormalities have been extensively studied because of their high frequency and clinical implications. Based on recent studies, coagulopathy has been recognized in the most severely ill patients, frequently presenting a DIC-like massive intravascular clot formation.

Pathophysiologically, COVID-19 coagulopathy has not been fully clarified yet, even though the underlying mechanisms may partially overlap those of a bacterial sepsis-induced coagulopathy and DIC. ${ }^{66}$ Furthermore, hypoxia has shown to play a role in thrombus formation and propagation, through the activation of cellular pathways including hypoxia-inducible factors (HIFs), such
HIF1 and HIF2. These molecules enhance the transcription of genes coding for proteins involved in coagulation homeostasis, including PAI-1. In addition, hypoxia may increase the release of inflammatory cytokines and reduce thrombomodulin levels, resulting in an overall prothrombotic effect unbalanced by a reduced fibrinolytic response. ${ }^{67}$

Despite some similarities, coagulopathy in COVID-19 shows peculiar hallmarks: in comparison with bacterialsepsis-induced coagulopathy, prolongation of PT and aPTT and decrease in antithrombin activity are less frequent in COVID-19. Thrombocytopenia is relatively uncommon, while thrombocytosis is recognized in the most severe cases. However, one of the typical features of coagulation disorder in COVID-19 is the predominant increase of the D-dimer, which appears to parallel the severity of the disease. $^{66}$

Tang et al analyzed retrospectively conventional coagulation results and outcomes of 183 consecutive patients with confirmed COVID-19 pneumonia: upon admission, non-survivors revealed significantly higher D-dimer and FDP levels, longer PT and aPTT compared to survivors ( $p$ $<0.05){ }^{68}$

However, a reliable D-dimer cut-off level on admission to predict in-hospital mortality in these patients has not been defined. Zhang et al dichotomized 343 patients in two groups based on the D-dimer cut-off value of $2000 \mathrm{ng} / \mathrm{mL}$ (four-fold the normal cutoff), which was found to be able to predict inhospital mortality with a sensitivity of $92.3 \%$ and a specificity of $83.3 \%$. Patients with D-dimer levels $\geq 2000 \mathrm{ng} / \mathrm{mL}$ had a higher mortality rate than those with D-dimer levels $<2000$ $\mathrm{ng} / \mathrm{mL}^{69}$ In a preliminary analysis of a sample of 140 patients, treated with non-invasive ventilation for acute respiratory failure due to COVID-19 and followed for several days at the beginning of the ventilator support (unpublished data), we found that the D-dimer level decreased in survivors, while showing a late increase in non-survivors. However, the dispersion of values was so wide that we did not find any significant difference based on prognosis (Figure 5).

Besides the prognostic role, the elevation of $\mathrm{D}$-dimer level in patients with COVID-19 has a therapeutic importance, concerning VTE prophylaxis. In Tang et al's trial, 449 COVID-19 patients were enrolled: 94 received 40 $60 \mathrm{mg} /$ day of enoxaparin and 5 received 10.000-15.000 U/ day of unfractionated heparin. The 28-day mortality of heparin users was lower than that of non-users, among patients who had a D-dimer value $>3000 \mathrm{ng} / \mathrm{mL}$ (ie, sixfold higher than the normal upper limit). Mortality rate did 

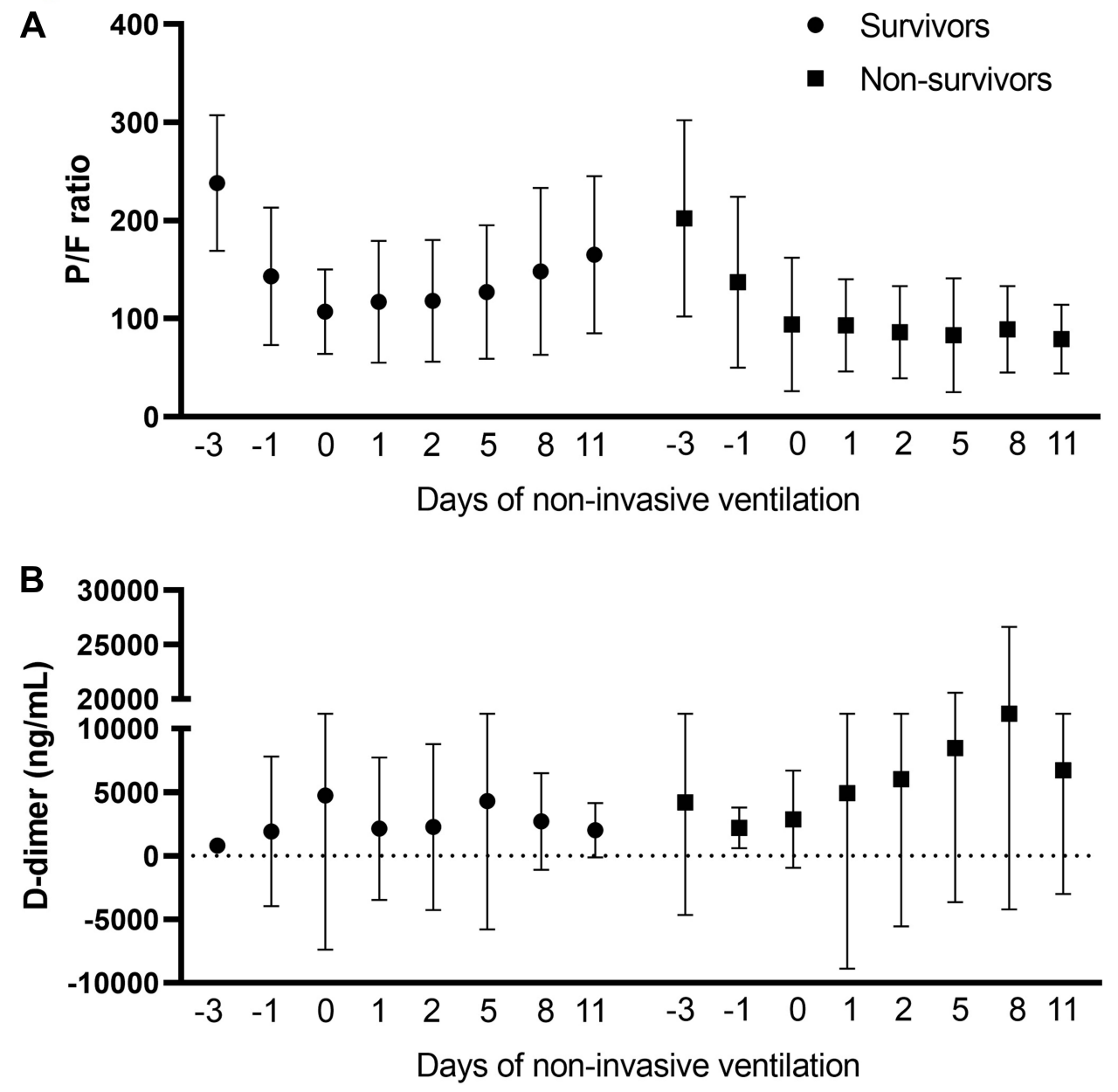

Figure 5 Trends of $\mathrm{PaO}_{2} / \mathrm{FiO}_{2}(\mathrm{P} / \mathrm{F})$ ratio $(\mathbf{A})$ and $\mathrm{D}$-dimer $(\mathbf{B})$ in survivors and non-survivors during the first days of the treatment with non-invasive ventilation for acute respiratory failure, in patients affected by SARS COVID-19.

not differ among heparin users according to D-dimer values. However, mortality raised alongside the increase in the D-dimer in non-users. When the D-dimer levels reached six-folds the normal upper limit, a reduction of $20 \%$ in mortality rate was found in heparin users compared to non-users $(32.8 \%$ vs $52.4 \% ; \mathrm{p}=0.017)$. $^{70}$

\section{Conclusions}

D-dimer represents a useful and cheap test, easily available in most EDs, which can add relevant diagnostic and prognostic information in the workup of a relevant proportion of patients visiting the ED. Knowing which patients will benefit from a determination of the D-dimer level and selecting them appropriately can help the Emergency Physician avoid unnecessary imaging tests, without increasing the risk of misdiagnosing. The employment of the D-dimer as a prognosticator needs to be confirmed in large prospective studies, as well as its role in guiding treatment.

\section{Disclosure}

The authors report no conflicts of interest in this work.

\section{References}

1. Johnson ED, Schell JC, Rodgers GM. The D-dimer assay. Am J Hematol. 2019;94(7):833-839. doi:10.1002/ajh.25482

2. Weitz JI, Fredenburgh JC, Eikelboom JW. A test in context: D-dimer. $J$ Am Coll Cardiol. 2017;70(19):2411-2420. doi:10.1016/j.jacc.2017. 09.024

3. Favresse J, Lippi G, Roy PM, et al. D-dimer: preanalytical, analytical, postanalytical variables, and clinical applications. Crit Rev Clin Lab Sci. 2018;55(8):548-577. doi:10.1080/10408363.2018.1529734

4. Lippi G, Bonfanti L, Saccenti C, Cervellin G. Causes of elevated D-dimer in patients admitted to a large urban emergency department. Eur J Intern Med. 2014;25(1):45-48. doi:10.1016/j.ejim.2013.07.012

5. Parshall MB, Schwartzstein RM, Adams L, et al. An official American Thoracic Society statement: update on the mechanisms, assessment, and management of dyspnea. Am J Respir Crit Care Med. 2012;185 (4):435-452. doi:10.1164/rccm.201111-2042ST

6. Breidthardt T, Laule K, Strohmeyer AH, et al. Medical and economic long-term effects of B-type natriuretic peptide testing in patients with acute dyspnea. Clin Chem. 2007;53(8):1415-1422. doi:10.1373/ clinchem.2006.081448 
7. Berdagué P, Caffin PY, Barazer I, et al. Use of N-terminal prohormone brain natriuretic peptide assay for etiologic diagnosis of acute dyspnea in elderly patients. Am Heart J. 2006;151(3):690-698. doi:10.1016/j.ahj.2005.04.004

8. Chen JY, Chao TH, Guo YL, et al. A simplified clinical model to predict pulmonary embolism in patients with acute dyspnea. Int Heart J. 2006;47(2):259-271. doi:10.1536/ihj.47.259

9. Stein PD, Terrin ML, Hales CA, et al. Clinical, laboratory, roentgenographic, and electrocardiographic findings in patients with acute pulmonary embolism and no pre-existing cardiac or pulmonary disease. Chest. 1991;100(3):598-603. doi:10.1378/chest.100.3.598

10. Miniati M, Prediletto R, Formichi B, et al. Accuracy of clinical assessment in the diagnosis of pulmonary embolism. Am J Respir Crit Care Med. 1999;159(3):864-871. doi:10.1164/ajrccm.159.3. 9806130

11. Stein PD, Beemath A, Matta F, et al. Clinical characteristics of patients with acute pulmonary embolism: data from PIOPED II. Am J Med. 2007;120(10):871-879. doi:10.1016/j.amjmed.2007.03.024

12. Pollack CV, Schreiber D, Goldhaber SZ, et al. Clinical characteristics, management, and outcomes of patients diagnosed with acute pulmonary embolism in the emergency department: initial report of EMPEROR (Multicenter Emergency Medicine Pulmonary Embolism in the Real World Registry). J Am Coll Cardiol. 2011;57(6):700-706. doi:10.1016/j.jacc.2010.05.071

13. Stokes NR, Dietz BW, Liang JJ. Cardiopulmonary laboratory biomarkers in the evaluation of acute dyspnea. Open Access Emerg Med. 2016;8:35-45. doi:10.2147/oaem.S71446

14. Konstantinides SV, Meyer G, Becattini C, et al. ESC Guidelines for the diagnosis and management of acute pulmonary embolism developed in collaboration with the European Respiratory Society (ERS): the Task Force for the diagnosis and management of acute pulmonary embolism of the European Society of Cardiology (ESC). Eur Respir J. 2019;2019;54(3). doi:10.1183/13993003.01647-2019

15. Brignole M, Moya A, de Lange FJ, et al. 2018 ESC guidelines for the diagnosis and management of syncope. Eur Heart J. 2018;39 (21):1883-1948. doi:10.1093/eurheartj/ehy037

16. Puppala VK, Dickinson O, Benditt DG. Syncope: classification and risk stratification. J Cardiol. 2014;63(3):171-177. doi:10.1016/j. jjcc.2013.03.019

17. Barco S, Ende-Verhaar YM, Becattini C, et al. Differential impact of syncope on the prognosis of patients with acute pulmonary embolism: a systematic review and meta-analysis. Eur Heart J. 2018;39 (47):4186-4195. doi:10.1093/eurheartj/ehy631

18. Keller K, Beule J, Balzer JO, Dippold W. Syncope and collapse in acute pulmonary embolism. Am $J$ Emerg Med. 2016;34 (7):1251-1257. doi:10.1016/j.ajem.2016.03.061

19. Prandoni P, Lensing AW, Prins MH, et al. Prevalence of pulmonary embolism among patients hospitalized for syncope. $N$ Engl J Med. 2016;375(16):1524-1531. doi:10.1056/NEJMoa1602172

20. Badertscher P, Du Fay de Lavallaz J, Hammerer-Lercher A, et al. Prevalence of pulmonary embolism in patients with syncope. $\mathrm{J} \mathrm{Am}$ Coll Cardiol. 2019;74(6):744-754. doi:10.1016/j.jacc.2019.06.020

21. Frizell A, Fogel N, Steenblik J, Carlson M, Bledsoe J, Madsen T. Prevalence of pulmonary embolism in patients presenting to the emergency department with syncope. Am J Emerg Med. 2018;36 (2):253-256. doi:10.1016/j.ajem.2017.07.090

22. Costantino G, Ruwald MH, Quinn J, et al. Prevalence of pulmonary embolism in patients with syncope. JAMA Intern Med. 2018;178 (3):356-362. doi:10.1001/jamainternmed.2017.8175

23. Long B, Koyfman A, Gottlieb M. Prevalence of pulmonary embolism in patients presenting with syncope. Acad Emerg Med. 2019;26 (5):571-573. doi:10.1111/acem.13700

24. Rodger MA, Carrier M, Jones GN, et al. Diagnostic value of arterial blood gas measurement in suspected pulmonary embolism. Am J Respir Crit Care Med. 2000;162(6):2105-2108. doi:10.1164/ ajrccm.162.6.2004204
25. Stein PD, Goldhaber SZ, Henry JW, Miller AC. Arterial blood gas analysis in the assessment of suspected acute pulmonary embolism. Chest. 1996;109(1):78-81. doi:10.1378/chest.109.1.78

26. White RH. The epidemiology of venous thromboembolism. Circulation. 2003;107(23 Suppl 1):I4-8. doi:10.1161/01.CIR.00 00078468.11849 .66

27. Buchanan I, Teeples T, Carlson M, Steenblik J, Bledsoe J, Madsen T. Pulmonary embolism testing among emergency department patients who are pulmonary embolism rule-out criteria negative. Acad Emerg Med. 2017;24(11):1369-1376. doi:10.1111/acem.13270

28. Roy PM, Friou E, Germeau B, et al. Derivation and validation of a 4-level clinical pretest probability score for suspected pulmonary embolism to safely decrease imaging testing. JAMA Cardiol. 2021;6 (6):669-677. doi:10.1001/jamacardio.2021.0064

29. Bates SM. D-dimer assays in diagnosis and management of thrombotic and bleeding disorders. Semin Thromb Hemost. 2012;38 (7):673-682. doi:10.1055/s-0032-1326782

30. Ceriani E, Combescure C, Le Gal G, et al. Clinical prediction rules for pulmonary embolism: a systematic review and meta-analysis. $J$ Thromb Haemost. 2010;8(5):957-970. doi:10.1111/j.1538-7836.2010.03801.x

31. Linkins LA, Takach Lapner S. Review of D-dimer testing: good, bad, and ugly. Int J Lab Hematol. 2017;39(Suppl 1):98-103. doi:10.1111/ ijlh. 12665

32. van der Hulle T, Cheung WY, Kooij S, et al. Simplified diagnostic management of suspected pulmonary embolism (the YEARS study): a prospective, multicentre, cohort study. Lancet. 2017;390 (10091):289-297. doi:10.1016/s0140-6736(17)30885-1

33. Kearon C, de Wit K, Parpia S, et al. Diagnosis of pulmonary embolism with D-dimer adjusted to clinical probability. $N$ Engl $J$ Med. 2019;381(22):2125-2134. doi:10.1056/NEJMoa1909159

34. Gibson NS, Sohne M, Gerdes VEA, Nijkeuter M, Buller HR. The importance of clinical probability assessment in interpreting a normal d-dimer in patients with suspected pulmonary embolism. Chest. 2008;134(4):789-793. doi:10.1378/chest.08-0344

35. Pitts SR, Niska RW, Xu J, Burt CW. National hospital ambulatory medical care survey: 2006 emergency department summary. Natl Health Stat Report. 2008;7:1-38.

36. Kim JY, Kim KH, Cho JY, et al. D-dimer/troponin ratio in the differential diagnosis of acute pulmonary embolism from non-ST elevation myocardial infarction. Korean J Intern Med. 2019;34 (6):1263-1271. doi:10.3904/kjim.2018.153

37. Ohle R, Um J, Anjum O, et al. High risk clinical features for acute aortic dissection: a case-control study. Acad Emerg Med. 2018;25 (4):378-387. doi:10.1111/acem.13356

38. Erbel R, Aboyans V, Boileau C, et al. 2014 ESC guidelines on the diagnosis and treatment of aortic diseases: document covering acute and chronic aortic diseases of the thoracic and abdominal aorta of the adult. The Task Force for the Diagnosis and Treatment of Aortic Diseases of the European Society of Cardiology (ESC). Eur Heart J. 2014;35(41):2873-2926. doi:10.1093/eurheartj/ehu281

39. Hiratzka LF, Bakris GL, Beckman JA, et al. 2010 ACCF/AHA/ AATS/ACR/ASA/SCA/SCAI/SIR/STS/SVM guidelines for the diagnosis and management of patients with thoracic aortic disease: executive summary. A report of the American College of Cardiology Foundation/American Heart Association Task Force on Practice Guidelines, American Association for Thoracic Surgery, American College of Radiology, American Stroke Association, Society of Cardiovascular Anesthesiologists, Society for Cardiovascular Angiography and Interventions, Society of Interventional Radiology, Society of Thoracic Surgeons, and Society for Vascular Medicine. Catheter Cardiovasc Interv. 2010;76(2):E43-86. doi:10.1002/ccd.22537

40. Mussa FF, Horton JD, Moridzadeh R, Nicholson J, Trimarchi S, Eagle KA. Acute aortic dissection and intramural hematoma: a systematic review. JAMA. 2016;316(7):754-763. doi:10.1001/ jama.2016.10026 
41. Evangelista A, Isselbacher EM, Bossone E, et al. Insights from the International Registry of Acute Aortic Dissection: a 20-year experience of collaborative clinical research. Circulation. 2018;137 (17):1846-1860. doi:10.1161/CIRCULATIONAHA.117.031264

42. Harris KM, Braverman AC, Eagle KA, et al. Acute aortic intramural hematoma: an analysis from the International Registry of Acute Aortic Dissection. Circulation. 2012;126(11 Suppl 1):S91-96. doi:10.1161/circulationaha.111.084541

43. Evangelista A, Czerny M, Nienaber C, et al. Interdisciplinary expert consensus on management of type B intramural haematoma and penetrating aortic ulcer. Eur J Cardiothorac Surg. 2015;47 (2):209-217. doi:10.1093/ejcts/ezu386

44. Ohle R, Kareemi HK, Wells G, Perry JJ. Clinical examination for acute aortic dissection: a systematic review and meta-analysis. Acad Emerg Med. 2018;25(4):397-412. doi:10.1111/acem.13360

45. Hagan PG, Nienaber CA, Isselbacher EM, et al. The International Registry of Acute Aortic Dissection (IRAD): new insights into an old disease. JAMA. 2000;283(7):897-903. doi:10.1001/jama.283.7.897

46. Harris KM, Strauss CE, Eagle KA, et al. Correlates of delayed recognition and treatment of acute type $A$ aortic dissection: the International Registry of Acute Aortic Dissection (IRAD). Circulation. 2011;124(18):1911-1918. doi:10.1161/ CIRCULATIONAHA. 110.006320

47. Nazerian P, Mueller C, Soeiro AM, et al. Diagnostic accuracy of the aortic dissection detection risk score plus D-Dimer for acute aortic syndromes: the ADvISED prospective multicenter study. Circulation. 2018;137(3):250-258. doi:10.1161/circulationaha.117.029457

48. Morello F, Santoro M, Fargion AT, Grifoni S, Nazerian P. Diagnosis and management of acute aortic syndromes in the emergency department. Intern Emerg Med. 2021;16(1):171-181. doi:10.1007/ s11739-020-02354-8

49. Righini M, Goehring C, Bounameaux H, Perrier A. Effects of age on the performance of common diagnostic tests for pulmonary embolism. Am J Med. 2000;109(5):357-361. doi:10.1016/s00029343(00)00493-9

50. Tita-Nwa F, Bos A, Adjei A, Ershler WB, Longo DL, Ferrucci L. Correlates of D-dimer in older persons. Aging Clin Exp Res. 2010;22 (1):20-23. doi:10.1007/bf03324810

51. Righini M, Van Es J, Den Exter PL, et al. Age-adjusted D-dimer cutoff levels to rule out pulmonary embolism: the ADJUST-PE study. JAMA. 2014;311(11):1117-1124. doi:10.1001/jama.2014. 2135

52. Pfortmueller CA, Lindner G, Funk GC, et al. Role of D-Dimer testing in venous thromboembolism with concomitant renal insufficiency in critical care. Intensive Care Med. 2017;43(3):470-471. doi:10.1007/ s00134-016-4646-3

53. Schefold JC, Gerber JL, Angehrn MC, et al. Renal function-adjusted D-dimer levels in critically ill patients with suspected thromboembolism. Crit Care Med. 2020;48(4):e270-e276. doi: $10.1097 / \mathrm{ccm} .0000000000004204$

54. Rhodes A, Evans LE, Alhazzani W, et al. Surviving sepsis campaign: international guidelines for management of sepsis and septic shock: 2016. Intensive Care Med. 2017;43(3):304-377. doi:10.1007/s00134017-4683-6
55. Singer M, Deutschman CS, Seymour CW, et al. The Third International Consensus Definitions for Sepsis and Septic Shock (Sepsis-3). JAMA . 2016;315(8):801-810. doi:10.1001/jama.2016. 0287

56. Suarez De La Rica A, Gilsanz F, Maseda E. Epidemiologic trends of sepsis in western countries. Ann Transl Med. 2016;4(17):325. doi:10.21037/atm.2016.08.59

57. Lelubre C, Vincent JL. Mechanisms and treatment of organ failure in sepsis. Nat Rev Nephrol. 2018;14(7):417-427. doi:10.1038/s41581018-0005-7

58. Levi M, Poll T. Coagulation in patients with severe sepsis. Semin Thromb Hemost. 2015;41(1):9-15. doi:10.1055/s-0034-1398376

59. Iba T, Levi M, Levy JH. Sepsis-induced coagulopathy and disseminated intravascular coagulation. Semin Thromb Hemost. 2020;46 (1):89-95. doi:10.1055/s-0039-1694995

60. Iba T, Levy JH, Warkentin TE, et al. Diagnosis and management of sepsis-induced coagulopathy and disseminated intravascular coagulation. J Thromb Haemost. 2019;17(11):1989-1994. doi:10.1111/jth.14578

61. Patel P, Walborn A, Rondina M, Fareed J, Hoppensteadt D. Markers of inflammation and infection in sepsis and disseminated intravascular coagulation. Clin Appl Thromb Hemost. 2019;25:1076 029619843338. doi:10.1177/1076029619843338

62. Seymour CW, Liu VX, Iwashyna TJ, et al. Assessment of clinical criteria for sepsis: for the third international consensus definitions for Sepsis and Septic Shock (Sepsis-3). JAMA. 2016;315(8):762-774. doi:10.1001/jama.2016.0288

63. Innocenti F, Gori AM, Giusti B, et al. Prognostic value of sepsis-induced coagulation abnormalities: an early assessment in the emergency department. Intern Emerg Med. 2019;14(3):459-466. doi:10.1007/s11739-018-1990-z

64. Rodelo JR, De la Rosa G, Valencia ML, et al. D-dimer is a significant prognostic factor in patients with suspected infection and sepsis. $\mathrm{Am}$ J Emerg Med. 2012;30(9):1991-1999. doi:10.1016/j.ajem.2012.04.033

65. Wiersinga WJ, Rhodes A, Cheng AC, Peacock SJ, Prescott HC. Pathophysiology, transmission, diagnosis, and treatment of Coronavirus Disease 2019 (COVID-19): a review. JAMA. 2020;324 (8):782-793. doi:10.1001/jama.2020.12839

66. Iba T, Levy JH, Levi M, Thachil J. Coagulopathy in COVID-19. $J$ Thromb Haemost. 2020;18(9):2103-2109. doi:10.1111/jth.14975

67. Vidali S, Morosetti D, Cossu E, et al. D-dimer as an indicator of prognosis in SARS-CoV-2 infection: a systematic review. ERJ Open Res. 2020;6(2). doi:10.1183/23120541.00260-2020

68. Tang N, Li D, Wang X, Sun Z. Abnormal coagulation parameters are associated with poor prognosis in patients with novel coronavirus pneumonia. J Thromb Haemost. 2020;18(4):844-847. doi:10.1111/ jth. 14768

69. Zhang L, Yan X, Fan Q, et al. D-dimer levels on admission to predict in-hospital mortality in patients with Covid-19. J Thromb Haemost. 2020;18(6):1324-1329. doi:10.1111/jth.14859

70. Tang N, Bai H, Chen X, Gong J, Li D, Sun Z. Anticoagulant treatment is associated with decreased mortality in severe coronavirus disease 2019 patients with coagulopathy. J Thromb Haemost. 2020;18(5):1094-1099. doi:10.1111/jth.14817

Open Access Emergency Medicine

Dovepress

Publish your work in this journal

The Open Access Emergency Medicine is an international, peerreviewed, open access journal publishing original research, reports, editorials, reviews and commentaries on all aspects of emergency medicine. The manuscript management system is completely online

and includes a very quick and fair peer-review system, which is all easy to use. Visit http://www.dovepress.com/testimonials.php to read real quotes from published authors. 